\title{
Malum Perforans Pedis - Case Report
}

\author{
Antigona Begolli Gerqari ${ }^{1,}$ ", Mybera Ferizi ${ }^{1}$, Sadije Halimi ${ }^{1}$, Aferdita Daka ${ }^{1}$, Syzana Hapciu ${ }^{1}$, \\ Ilir Begolli ${ }^{2}$, Mirije Begolli ${ }^{3}$, Idriz Gerqari ${ }^{4}$ \\ ${ }^{1}$ Dermatovenerology Clinic, University Clinical Center, Prishtina, Republic of Kosovo \\ ${ }^{2}$ National Public Health Institute, Prishtina, Republic of Kosovo \\ ${ }^{3}$ Pediatric Clinic-University Clinical Center, Prishtina, Republic of Kosovo \\ ${ }^{4}$ Nuclear Medicine Department-University Clinical Center, Prishtina, Republic of Kosovo
}

\section{Email address:}

antigonagerqari@gmail.com (A. B. Gerqari),myberaf@hotmail.com (M. Ferizi), sadijehalimi@gmail.com (S. Halimi), aferditadaka@gmail.com (A. Daka),syzanahapciu@yahoo.com (S. Hapciu), ilirbegolli@gmail.com (I. Begolli), mirijeb@yahoo.com (M. Begolli), idrizgerqari@yahoo.com (I. Gerqari)

${ }^{*}$ Corresponding author

\section{To cite this article:}

Antigona Begolli Gerqari, Mybera Ferizi, Sadije Halimi, Aferdita Daka, Syzana Hapciu, Ilir Begolli, Mirije Begolli, Idriz Gerqari. Malum Perforans Pedis - Case Report. Science Journal of Clinical Medicine. Vol. 5, No. 3, 2016, pp. 29-31. doi: 10.11648/j.sjcm.20160503.11

Received: March 15, 2016; Accepted: March 31, 2016; Published: April 25, 2016

\begin{abstract}
Background: Malum perforans pedis is a chronic disease characterized by a punched out ulceration that may enlarge. The ulcer is localisated in a foot. It is a complication of the primary disease of the different origin that is always presented with a vaculopathies or neuropathies, and is common in diabetic patients. Malum perforans pedis appears in a sole of the foot and mostly occurs with no pain. The disease is mostly caused by the pressing of the underlain bone and a chronic trauma on a poor blood flow of the tissue. The treatment consists: on a treatment of the primary disease-vaculopathy and neuropathy; the local treatment includes treatment of the infection and the wound treatment through surgery and skin grafting. Case presentation: This paper presents a case of a 49 year old woman with the ulceration on a sole of the left foot that did appeared before four months. The patient claims that the changes began after wearing shoes that hurt her foot. The patient also claims that during the past year she had some signs of diabetes and the measure of the blood sugar shows high levels. The patient also gives interesting data that during the last few years she have had used cosmetics which contained mercury. Conclusions: Malum perforans pedis is a disease where the patient loses the feeling of pain and the chronic trauma causes the injury and following that during the time the defect in a skin enlarges and makes a trophic ulcer in a various size and form. It also depends on a microangiopathies due to diabetes and arteriosclerosis.
\end{abstract}

Keywords: Malum Perforans Pedis, Diabetes Mellitus, Diabetic Foot

\section{Introduction}

Malum perforans pedis is a chronic ulceration in the sole of the foot that is caused by a long term trauma, accompanied with other pathological states: metabolic, infective and degenerative diseases. The ulcer has a more perforating form and shows in the situation of neuropathies accomplished with trophic problems of the tissue where the changes appear [1]. The disease affects both males and females with a predomination of the first group. Malum perforans pedis appears in all ages with predomination of the elderly and middle ages.
The ulcers caused in malum perforans pedis are mostly without symptoms, there is no pain, but in some cases the patient may describe the changes with some discomfort in walking [3]. Probably because the ulcers begins in a hyperkeratosis base, the ulcer during that time forms the round wall with a hard callus.

The cause of malum perforans pedis is based on a long term injury at the pressure bearing areas, neurologic diseases such as: arteriosclerosis, diabetes mellitus, leprosy, lues and lumbosacral plexus, as well as intrathecal tumors.

The diagnosis is made based on a history of previous neurotrophic disease and typical skin signs in correct localizations. 


\section{Case Report}

A 49 year old female Albanian patient was referred to a dermatologist from a family doctor with complaints for long term ulcer on a base of the hyperkeratotic callus on a sole of the left foot. The local examination highlights shows deep perforating ulcer of the heel with surrounding callosity. The size of the ulcer was $3 \times 2 \mathrm{~cm}$ and $0.8 \mathrm{~cm}$ in depth. The base of the ulcer shows the signs of the secondary bacterial infection. The ulcer was painless, but the patient had discomfort while walking. The patient was hospitalized and a routine analysis was conducted. The analysis revealed high blood sedimentation and leukocytosis with a mild increase in the level of sugar in blood. The patient had latent diabetes for years and was treated with a metformin for a while, but stopped taking medicine for more than 5 months. In addition, in an anamnesis report the patient did mention that she was using cosmetics with concentrate of mercury for years while claiming to have stopped using that cosmetic 3 years ago.

The patient was also treated by the rheumatologist for ankle and back pain but she was not consequent in a treatment

During hospitalization the patient was treated with antibiotics, and since we detected interdigital candida the antimitotic and local treatment consisted in applying antibiotics and restorative cream with hyaluronic acid. The X-ray examination was done to exclude osteomyelitis and because there was no sign of the bone being harmed the debridement of the surrounding callus was done. The patient was released from hospital in a much better condition for continued home treatment. The patients were admitted several times in routine control and her condition was under improvement .She was also regularly visiting the endocrinologist and the level of a blood sugar was under the referent values.

\section{Discussion}

Malum perforans pedis is a neurovascular disease mostly in the skin with abnormal innervations with impaired perfusion, developing ulceration in the foot accompanied with a loss of pain sensation $[5,1]$. The ulcers is most likely to develop under the hyperkeratosis skin or over on a callus [3]. The ulcer is deep with sharply elevated borders and a granulomatosis base. It may occur in any age to a person with a neuropathy, diabetes, syphilis, leprosy, or spinal nerve disease [6]. Since the loss of the pain sensation in this patients leads to less small injuries the attention of the patient is not so good so the damage of the skin is more possible.

The association of malum perforans pedis with diabetes mellitus and other neuropathies is obvious. The etiology of malum perforans pedisis is mostly connected with this disease.

The iatrogenic origin of the lesions has also been stated, due to a small injury, especially chronic injuries such as: while walking with inappropriate shoes leads to skin breakdown and respective ulceration. Neuropathic ulcers develop in a site of repetitive high pressure, in people with a peripheral sensory deficit [2].

The treatment is difficult based on a different origin of the foot ulcer. It consists on the identification of the ethyology of the skin defect resulting with the ulcer, as well as avoiding a local factor such as injury v very important in appearance of the disease. The proper anamnesis will solve diagnostic problems such as neuropathic, diabetic, arterial, infectious or other primary diseases that lead to skin problems and final foot ulcer. The primary disease must be taken under control, including the consultation and multidisciplinary approach from endocrinologist, vascular surgeon and plastic surgeon as well, and then the treatment of the wound must be started [4]. Surgical debridement must include removal of the hyperkeratosis skin and callus. If there is infection of the skin, antibiotics should be administrated with a consultation from the orthopedic to avoid bone involvement.

\section{Conclusion}

Some internal diseases can have impact in the skin. Malum perforans pedis is a chronic inflammatory disease that maybe associated with some neurologic diseases, neurotrophic, as well as, with some endocrine diseases such as arteriosclerosis, diabetes mellitus, leprosy, lues and lumbosacral plexus, and intrathecal tumors $[5,2,1,6]$.

Malum perforans pedis is characterized by the presence of ulcer in the foot, mostly in a hyperkeratotic skin or in a callus. Our case of malum perforans pedis is associated with latent diabetes mellitus and the possibility of the chronic mercury poising.

The patients with malum perforans pedis, should avoid injuries resulting from long walks in inappropriate shoes and should have their blood sugar under control. Also the other causes of the disease should be managed [4].

The patients with malum perforans pedis need regular monitoring and multidisciplinary management of the disease.

\section{Authors' Contributions}

AG, MF, SH, AD, IB, MB, IG analyzed and interpreted the patient's data. AG was a major contributor in writing the manuscript. All authors read and approved the final manuscript.

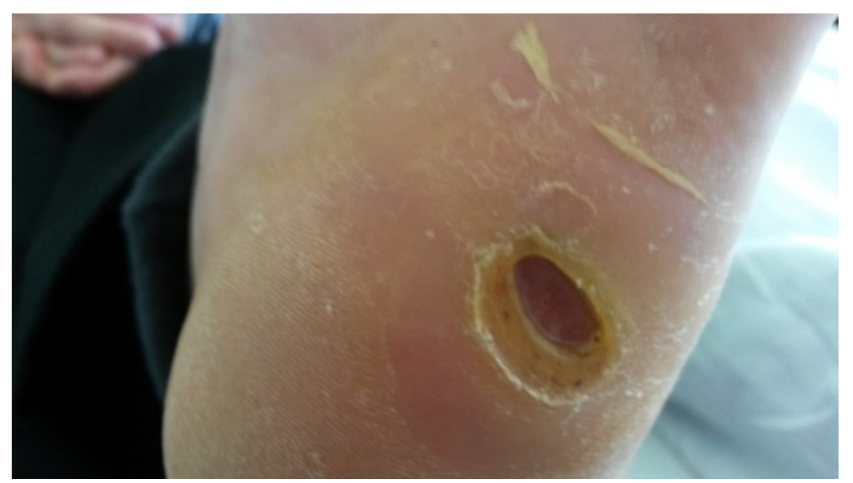

Figure 1. Malum perforans pedis in previous callus. 


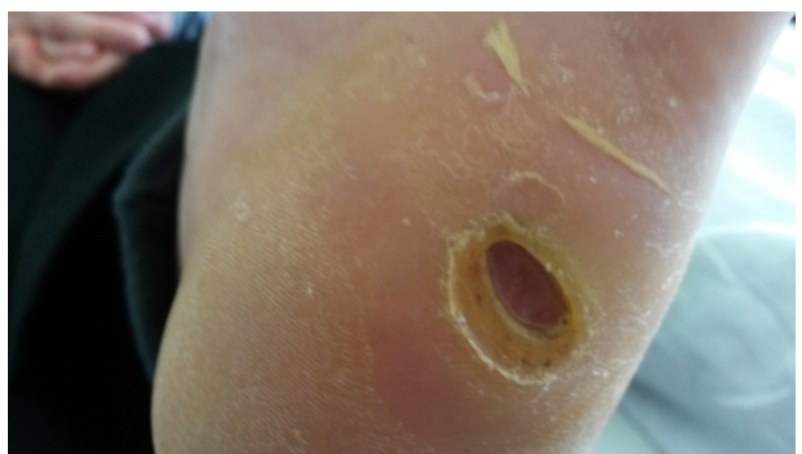

Figure 2. Malum perforans pedis.

\section{Acknowledgements}

The authors would like to acknowledge the Department of Dermatovenerology, the Department of Physical Therapy within the Dermatovenerology Department clinic for their commitment and collaboration.

\section{References}

[1] Tesch M. Spinal claudication and malum perforans pedis. Late sequela of ankylosing spondylitis (Bechterew disease) with cystic lumbosacral arachnopathy. Nervenarzt 1994; 65: 874-7.

[2] Nishio K, Yamamoto O, Tsukahara J. Malum perforans pedis caused by spinal canal stenosis and spondylolisthesis. J UOEH 1984; 6:171-6.
[3] Shaw JE, Hsi WL, Ulbrecht JS, Norkitis A, BeckerMB, Cavanagh PR. The mechanism of plantar unloadingin total contact casts: implications for designand clinical use. Foot Ankle Int 1997; 18: 809-17.

[4] Steed DL. Clinical evaluation of recombinant human Plateletderived growth factor for the treatment of lower extremity ulcers. Plast Reconstr Surg. 2006; 117(Suppl 7): 143S-149S.

[5] James WD, Berger TG, Elston DM. Pruritus and neurocutaneous dermatoses, Andrews diseases of the skin clinical dermatology, 10th edition, ElsevierInc. 2006. p. 65-66.

[6] Shats EI, Iushchenko AA. Clinico-epidemiologic characteristics of neurotrophic ulcers of the feet in patients with leprosy. VestnDermatolVenerol1988; 12: 37-41.

[7] Neuropathic pain - pharmacological management: The pharmacological management of neuropathic pain in adults in non-specialist settings; NICE Clinical Guideline (Nov 2013).

[8] Management of diabetes; Scottish Intercollegiate Guidelines Network - SIGN (March 2010).

[9] Type 2 diabetes: Prevention and management of foot problems; NICE Clinical Guideline (January 2004).

[10] Alavi A, Sibbald RG, Mayer D, et al; Diabetic foot ulcers: Part II. Management. J Am Acad Dermatol. 2014 Jan; 70(1): 21.e124; quiz 45-6. doi: 10.1016/j.jaad.2013.07.048.

[11] Vuorisalo S, Venermo M, Lepantalo M; Treatment of diabetic foot ulcers. J Cardiovasc Surg (Torino). 2009 Jun; 50(3): 27591. 